\title{
Prototype effects in discourse and the \\ synonymy issue: Two Lakota \\ postpositions*
}

REGINA PUSTET

\section{Abstract}

Despite of being fully synonymous at the semantic level, the postpositions él 'locativeldirectional' and ektá 'locativeldirectional' in Lakota (Siouan, Central North America) display different semantic cores in discourse: the semantic prototype for él is the role of locative, while the semantic prototype for ektá is the role of directional. Both the functional synonymy between él and ektá and the observed prototype effects can be attributed to constellations created by grammaticalization processes: when an innovative grammatical element is developing - in this case, ektá-replacement of a functionally equivalent older element-in this case, él-is unlikely to happen overnight, so that the innovative and the older element can be expected to coexist for a while, and to share functional domains.

Keywords: adpositions; prototypes; synonymy; discourse frequency; language change.

\section{Synonymy}

Everyday experience tells that perceived reality can be represented in alternative ways. Any given object, event, situation, etc. potentially lends itself to description by means of more than one linguistic unit, construction, clause, sentence, etc. A specific and well-known instantiation of the variability of linguistic description is the phenomenon of synonymy: presumably, in any one language, there are linguistic elements which convey the same meaning and can thus be substituted for each other in discourse. An example for synonymy is the English adjective pair big vs. large. Full synonymy is commonly regarded as an extremely rare, or even inexistent, semantic relation between linguistic items (cf., for instance, Haiman 1980: 516). As a matter of fact, it is often claimed that true synonymy does not 
actually exist at all because the distributional ranges of the linguistic items involved never overlap completely (e.g., Lyons 1968: 447). The difference in meaning between near-synonymous linguistic items is, in many cases, to be sought at the pragmatic or stylistic rather than at the semantic level:

Different terms serve to mark formality versus informality, directness versus indirectness, pretentiousness versus bluntness, distance versus solidarity, politeness versus indifference or rudeness, and so on. (Clark 1993: 73)

Frequently, the members of pairs of synonyms differ with respect to emotive coloring alone. An example of this constellation is the lexeme pair statesman vs. politician: "the former is laudatory and the latter is not" (Clark 1993: 73).

From the very beginnings of linguistics as an established science in the Western tradition, the synonymy issue has received extensive treatment in the theoretical literature; among others, earlier treatises that could be listed here are Bréal (1897) and Frei (1929). In the more recent literature, discussions of synonymy can be found in Bolinger (1977), Clark (1993: 72-74), Haiman (1985), and Levinson (2000: 135-146), for instance. What all these works have in common is that they motivate the scarcity of synonymy, either explicitly or implicitly, through the principle of cognitive economy. One of the paths that lead from cognitive economy to synonymy avoidance involves the "one meaning — one form" principle, also known as isomorphism (Haiman 1985: 14). In the case of synonymy, two or more forms express a single meaning or concept, or an identical set of meanings or concepts. Such instances of a one-to-many mapping of concepts in perceived reality onto linguistic categories violate the economy principle of categorization, since "cognitive economy dictates that categories tend to be viewed as being as separate from each other and as clear-cut as possible" (Rosch 1978: 36; also, cf. Geeraerts 1988: 225).

Further, particularly within the domain of lexical derivation, it has often been observed that near-synonyms may differ only with respect to their markedness status (e.g., Kiparsky 1982: 7). In this context, marked forms are characterized as "more morphologically complex and less lexicalized, more prolix or periphrastic, less frequent or usual, and less neutral in register" (Levinson 2000: 137) on the formal side; on the meaning side, they "suggest some additional meaning or connotation absent from the corresponding unmarked forms" (Levinson 2000: 137). Such divergency in markedness can be illustrated by means of two nominal derivations from the English verb to inform, viz., informer and informant:

... the regular, unmarked formation picks up the stereotypical extension, often narrowed in the typical way - so informer becomes not only 'one who informs' but 
also 'one who informs against his own'; informant is the marked derivation and picks up an exclusive (if not complementary) denotation, as in the linguistics usage. (Levinson 2000: 139)

Levinson (2000: 135-146), inspired by Horn (1984), traces markednessbased synonymy suppression back to Gricean maxims, from which he derives the so-called M-principle, which is defined as follows:

Speaker's maxim. Indicate an abnormal, nonstereotypical situation by using marked expressions that contrast with those you would use to describe the corresponding normal, stereotypical situation.

Recipient's corollary. What is said in an abnormal way indicates an abnormal situation, or marked messages indicate marked situations. (Levinson 2000: 136)

In essence, Levinson's M-principle, which maintains that formally marked linguistic items are used to convey semantically marked meanings, can be regarded as a manifestation of iconicity, one of the most fundamental principles that shape language structure. Since isomorphism, or the 'one meaning - one form principle', which has been identified as an additional stimulus for the avoidance of synonymy, is also a sub-principle of iconicity (Haiman 1985), all motivations for the general tendency of synonymy suppression are conditioned by the principle of iconicity. Iconic representation of meaning of whatever type, further, exceeds noniconic representation of meaning in cognitive economy (e.g., Givón 1985: 189). Thus, ultimately, both isomorphism and Levinson's M-principle are rooted in the obvious necessity of keeping linguistic expression as economical as possible.

Some empirical evidence for the process of synonymy suppression comes from lexical innovation and acquisition. With regard to diachronic development, "the condition on lexical innovations is that they must contrast in meaning with conventional lexical items" (Clark 1993: 80). Thus,

whenever an expression might have a complete synonym, the speaker must have a good reason for selecting it over its alternative; and the addressee, to satisfy unique computability, will try to find such a reason. (Clark 1993: 82)

This mechanism blocks the rise of synonyms since it

stops speakers from creating new expressions that are fully synonymous with old ones; and it forces them to add distinctions whenever they use one of two expressions that might otherwise be fully synonymous. (Clark 1993: 82) 
In acquisition, the categorical antisynonymy imperative may result in the expectation that the suppletive forms occurring in certain inflectional paradigms belong to the paradigm of a semantically distinct lexical item. This may keep children from identifying irregular inflectional forms such as English went as part of the paradigm of go. Consequently, children may use went and the parallel regular but ungrammatical form goed side by side for a considerable amount of time (Clark 1993: 103).

In what follows, two linguistic items which document the exceptionally rare case of true synonymy will be investigated in detail. The elements in question are the postpositions él and ektá in the Native American language Lakota (Siouan, central North America), both of which express the semantic roles of locative and directional. What makes these elements particularly interesting is that they seem to be fully synonymous in terms of all the criteria listed, that is, with respect to semantic, pragmatic, and even stylistic usage, as well as with respect to semantic markedness. However, there exists one area of investigation in which él and ektá exhibit quite distinct properties: frequency distribution in discourse. Thus, the main objective of the present investigation is calling attention to discourse as a potential additional, and quite subtle, level of linguistic description which offers the opportunity to evaluate potential synonymy relations. It appears that in traditional treatises on synonymy, this level of description has been neglected so far. The data discussed in what follows suggest that including the discourse level in research on synonyms should, in any given case, lead to a more differentiated picture of synonymy relations. In particular, the present study reveals that with respect to the discourse frequency of each of the possible meanings they convey, polysemous synonyms, such as the Lakota postpositions él and ektá, may display divergent semantic profiles. $E ́ l$ is used more frequently for coding a locative, rather than a directional, meaning, while ektá occurs more frequently as a marker for the role of directional, rather than as a marker for the role of locative. On these grounds, the role of locative can be identified as the semantic prototype of $e ́ l$, while the role of directional can be identified as the semantic prototype of ektá. It should be noted at this point that although frequency-based applications of prototype theory are not encountered very often in the cognitive literature, such approaches to prototypicality have certainly been proposed (e.g., Barsalou 1985).

The definition of "discourse" adopted for the purpose of this study is as follows: discourse is any coherent speech involving one or more speakers. Thus, narratives presented by a single speaker are included in the definition.

The language sample used consists of four text collections, three of which document different historical strata in the development of the 
Lakota language; the fourth text collection provides comparative data on the related dialect Dakota. All four text collections are similar in content in that they are composed of narratives which focus mostly on myths and autobiographical materials. The fact that all four data sources consist of narratives ensures parallelism in genre, so that differences in genre cannot be held responsible for the divergences regarding the use of the postpositions él and ektá which are investigated in this study.

The text source Pustet (to appear) comprises about 22,000 words. The materials were recorded in 1994 and 1995; all three native speakers consulted were in their seventies at the time of recording. The source Deloria (1932) contains about 70,000 words and comes from a single speaker, namely, from Ella Deloria herself (Rice 1994: 4). Deloria recorded texts from various native speakers, which she later retold in her own words. Some of these texts were compiled in 1931, but for the bulk of the data the time of recording is not specified. According to Rice (1994: 3), Deloria collected many of her texts "throughout the 1930s", when she was in her forties. The source Manhart (1978) is composed of about 57,000 words. The texts were recorded in 1904, and from 1915 to 1921. The age of the numerous informants at the time of recording, if specified, ranges between 63 and 78. The source Riggs (1973 [1893]) consists of about 11,000 words. The time of recording and the age of the speakers at the time of recording are unknown.

\section{The data from contemporary Lakota}

\section{1. Él vs. ektá: Preliminaries}

The Lakota postpositions él and ektá are full synonyms. They both code the semantic roles of locative and directional. Their semantic range is roughly equivalent to that of the English prepositions at, in, and on (in their locative readings) on the one hand, and $a t$, in, and on (in their directional readings), to, into, and onto, on the other. Testing for mutual substitutability in discourse is one criterion for determining whether linguistic elements are synonymous. The postpositions él and ektá cover precisely the same semantic space since they can, according to native speaker intuitions, be substituted for each other in all discourse contexts investigated. The corpus used for this purpose is Pustet (to appear), a collection of Lakota narratives which were recorded in the mid-1990s. Further detailed work with native speakers did not yield any data that would refute the claim that él and ektá are equivalent at the levels of pragmatic and stylistic description as well. Thus, the Lakota postpositions él and ektá provide 
Table 1. Feature matrix: Semantic range of él and ektá

\begin{tabular}{lll}
\hline & space & time \\
\hline stasis & space/stasis & time/stasis \\
kinesis & space/kinesis & time/kinesis \\
\hline
\end{tabular}

an example for the extremely rare constellation of complete overlap of linguistic items with respect to their functional range.

The semantic domain covered by él and ektá can be delimited by the features stasis vs. kinesis (or motionlessness vs. motion), and space vs. time. These features yield four different feature combinations, or semantic domains, which can be arranged in a feature matrix, as in Table 1. The four feature combinations depicted in Table 1 are exemplified by the following English examples:

(1) a. Space/stasis: in the house

b. Space/kinesis: to the house

c. Time/stasis: in summer

d. Time/kinesis: (we are getting closer) to the end of the year

In discourse, the feature combinations which contain the feature time occur much less frequently than those which contain the feature space. In particular, the combination kinesis/time is entirely absent in all discourse samples investigated in this study. (Test counts reveal that space specifications are much more frequent than time specifications in English discourse as well - this might be a universal property of discourse organization.) The interesting question of why this is so would deserve an in-depth investigation of its own; the issue is, however, not relevant for the research conducted in this study and will therefore not be pursued further in what follows.

Examples (2) to (5) illustrate the usage of the Lakota postpositions él and ektá. ${ }^{1}$

(2) thipi $k i$ él

C/DIR

'inlto the house'

(3) thípi ki ektá

house the LOC/DIR

'inlto the house'

(4) waniyetu $\mathrm{ki}$ él

winter the LOC/DIR

'inltowards winter' 
Table 2. Discourse distribution of feature combinations in Pustet (to appear)

\begin{tabular}{llc} 
& space & time \\
\hline stasis & 57 & 10 \\
kinesis & 59 & 0 \\
\hline
\end{tabular}

Table 3a. Discourse distribution of él and ektá in Pustet (to appear): Raw figures

\begin{tabular}{llllll}
\hline & \multicolumn{2}{c}{} & \multicolumn{2}{c}{ ektá } \\
\cline { 2 - 3 } & space & time & & space & time \\
\hline stasis & 31 & 5 & 26 & 5 \\
kinesis & 16 & 0 & 43 & 0 \\
\hline
\end{tabular}

$\begin{array}{lll}\text { (5) } \begin{array}{lll}\text { waniyetu } \\ \text { winter }\end{array} & k i & \text { ektá } \\ & \text { the } & \text { LOC/DIR }\end{array}$

'inltowards winter'

\subsection{Discourse distribution of él and ektá in Lakota Texts (Pustet, to appear)}

The frequency of occurrence of each of the feature combinations listed in Table 1 in a Lakota text corpus that comprises about 350 pages of narratives, i.e., Pustet (to appear), is given in Table 2.

The overall statistical frequencies of the two postpositions in the sample are more or less balanced: there are 52 occurrences of él in the corpus, which amounts to an overall percentage of 41.3 percent; the total for ektá is 74 , an overall percentage of 58.7 percent.

Of the four logically possible feature combinations listed in Table 1, only three are attested in the sample: space/stasis, space/kinesis, and time/ stasis. If él and ektá are indeed fully synonymous so that is does not matter which of the two postpositions is used in a given context, the relative frequencies of él and ektá within each of the three semantic domains (space/ stasis, space/kinesis, and time/stasis) should, more or less, equal the relative distribution of the competing postpositions in the overall sample. Thus, within each of these semantic domains, ektá should be slightly more frequent than él. This hypothesis, however, is not borne out by the statistical data, as the figures reproduced in Table $3 \mathrm{a}$ reveal. The raw figures given in Table 3a can be converted into a bar chart, as in Figure 1.

In Figure 1, the first column pair from the left represents the feature combination space/stasis, the central column the feature combination space/kinesis, and the first column from the right depicts the feature combination time/stasis. 


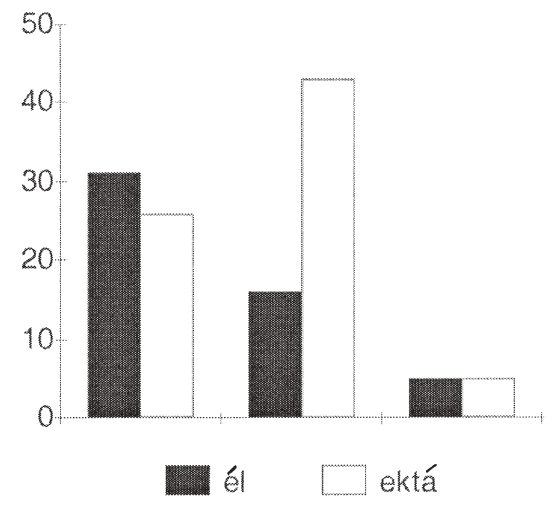

space/stasis space/kinesis time/stasis

Figure 1. Discourse distribution of él and ektá in Pustet (to appear)

Time/stasis yields five occurrences of él and five occurrences of ektá, and the resulting percentages $(50: 50$ percent for él vs. ektá) do not diverge too greatly from the ratio obtained for the overall sample (41.3 : 58.7 percent respectively). But the ratio for space/stasis reverses the prediction based on the overall sample, namely that ektá should be slightly more frequent than él: there are 31 occurrences of él and 26 occurrences of ektá (54.4 : 45.6 percent for él vs. ektá). The ratio for space/kinesis does not match the values obtained for the overall sample either; there are 16 occurrences of él and 43 occurrences of ektá (27.1 : 72.9 percent for él vs. ektá). Thus, within the space/kinesis domain, él is much less frequent than expected, while ektá is much more frequent than expected.

In sum, these values do not comply with the distribution calculated for the overall sample. As a matter of fact, the distributions of the two postpositions peak in different places in semantic space. Comparing the frequencies of occurrence of each of the three semantic feature combinations within the total set of occurrences of each postposition reveals that ektá clearly "favors" coding space/kinesis over coding space/stasis, and that él shows at least a slight preference for coding space/stasis rather than space/kinesis. The percentages indicating these preferences, which are derived from the raw figures given in Table $3 \mathrm{a}$, are shown in Table $3 \mathrm{~b}$.

Table 3b. Discourse distribution of él and ektá in Pustet (to appear): Percentages

\begin{tabular}{llll}
\hline & space/stasis & space/kinesis & time/stasis \\
\hline él & 59.6 & 30.8 & 9.6 \\
ektá & 35.1 & 58.1 & 6.8 \\
\hline
\end{tabular}


Thus, with each postposition a different "core meaning" (in the sense of Rosch 1973: 140) is associated. Given this tendency of specialization, semantic prototypes can be established for the two postpositions: the semantic prototype for él is space/stasis, while the prototype for ektá is space/kinesis. The fact that the semantic cores of the two postpositions are located in different places in semantic space implies that they are not truly synonymous, if synonymy is defined not only in semantic terms, i.e., merely on the basis of translation, but in statistical terms as well.

Constellations such as the one described for Lakota occur in other languages as well. For instance, Geeraerts (1988) reports that in nineteenthcentury Dutch, the verbs vernietigen 'to destroy' and vernielen 'to destroy' were functionally synonymous, i.e., could be used "indiscriminately with the same range of application" (Geeraerts 1988: 210), but exhibited different semantic preferences in discourse. In nineteenth-century Dutch texts, vernietigen tends to occur in contexts which require an abstract reading, while vernielen is more likely to be found in contexts implying physical destruction. Today, an anonymous reviewer for Cognitive Linguistics reports, full functional synonymy between the two verbs is lost.

It should be noted at this point that whenever the term prototype is used in this study, it should be interpreted as defined in quantitative terms only, that is, based on frequency in discourse. The original Roschean definition of the notion of prototype is much more comprehensive. It is derived from experimental results within the various subdimensions of the complex cognitive dimensions of learning and processing of categories. It is entirely possible that the discourse-based prototype structures described above have a reality at the cognitive level as well and that, therefore, assembling the relevant experimental data would confirm the statistical findings regarding the distribution of él and ektá in Lakota discourse which were presented in the foregoing discussion. However, with the exception of the exemplar naming experiment presented in section 2.3, such experimental data are not available at this time. The exemplar naming experiment has been conducted in the attempt to adduce at least some evidence in support of the hypothesis that the discourse-level prototype structures that emerge within the intrinsic semantic profiles of the Lakota postpositions él and ektá are anchored at a "deeper", cognitive, level as well.

\subsection{Distribution of él and ektá in an exemplar naming experiment in contemporary Lakota}

The issue addressed in the previous section can be approached from a different perspective by making use of a somewhat modified method of data compilation. With the Lakota native speaker who acted as the main 
Table 4. Discourse distribution of él and ektá in an exemplar naming experiment in contempotrary Lakota: Raw figures

\begin{tabular}{llllll}
\hline & \multicolumn{2}{c}{} & \multicolumn{2}{c}{$l$} & \multicolumn{2}{c}{ ektá } \\
\cline { 2 - 3 } & space & time & & space & time \\
\hline stasis & 21 & 1 & 10 & 0 \\
kinesis & 10 & 0 & 22 & 0 \\
\hline
\end{tabular}

informant in establishing the Pustet (to appear) text corpus and is therefore the main source of the figures presented in section 2.2, a so-called exemplar naming experiment has been conducted. In this experiment, the native speaker was asked to provide examples of sentences containing él and ektá. The experiment was completed at a point at which the speaker had given an equal number of example sentences for both él and ektá. The corpus contains 32 example sentences for él and ektá, respectively, i.e., a total of 64 example sentences.

As it turns out, the statistical correlations which emerge in the exemplar naming experiment are parallel to those obtained by the discourse counts described in section 2.2 (see Table 4).

The graphical representation of the raw figures given in Figure 2 demonstrates that the exemplar naming experiment produces the very same prototype effects that emerge in the discourse counts: the frequency of él (twenty-one occurrences for space/stasis, ten for space/kinesis, and one for time/stasis; in percentages: $65.6: 31.3: 3.1$ percent) peaks in space/stasis contexts, and more clearly so than in the discourse sample dealt with in

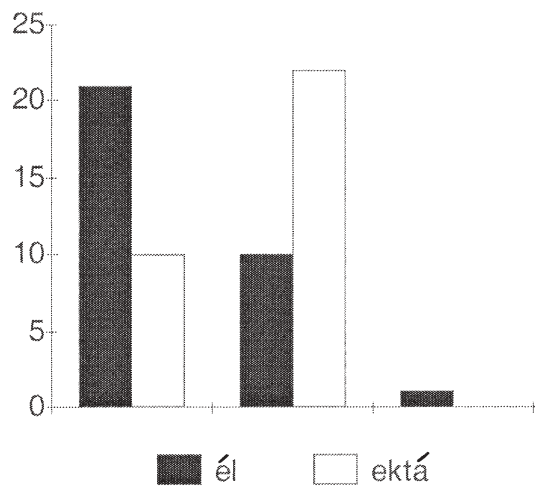

space/stasis space/kinesis time/stasis

Figure 2. Distribution of él and ektá in an exemplar naming experiment in contemporary Lakota 
section 2.2, while ektá peaks in space/kinesis contexts (ten occurrences for space/stasis, twenty-two for space/kinesis, and none for time/stasis; in percentages: $31.2: 68.8: 0.0$ percent). As a matter of fact, the distributional patterns in Figure 2 display prototype structures in which the relative distributional values of él and ektá within the semantic domains space/ stasis and space/kinesis are inversely symmetrical.

\section{Discourse-based prototypes and language change}

In many, if not all, areas of linguistic research, the inclusion of diachronic data results in a more differentiated outlook on a given problem. For this reason, investigating the distributional properties of the Lakota postpositions él and ektá in diachronic perspective as well might yield important insights.

Grammaticalization theory identifies various diachronic sources for adpositions: serial verbs, relational nouns such as designations of body parts, and adverbs (Heine et al. 1991). Lakota, by and large, derives its inventory of postpositions from serial verbs. In some cases, the respective postpositions are still phonetically identical with the source verbs. Some examples are listed in Table 5. For more details, cf. Pustet (2000).

The diachronic origin of the postposition ektá is not transparent, although a connection with the adverb ektánalektáni 'there (locative and directional)' can certainly not be denied. The postposition él derives from the verb étu 'to be there, be at/on, exist, be present, be ready'. Examples such as (6) illustrate the process of the transition between a verbal and postpositional interpretation of éllétu. The translation in square brackets renders the literal sense of the example if $e ́ l$ is given its original verbal translation.

$\begin{array}{llllll}\text { iyécikyake } & k i & \text { chakú } & k i & \text { él } & \text { náži } \\ \text { car } & \text { the } & \text { road } & \text { the } & \text { LOC } & \text { stand }\end{array}$
'The car is parked on the road.' ['The car stands being on the road.']

Table 5. Lakota postpositions and their verbal sources

\begin{tabular}{ll}
\hline Postpositions & Etymologically related verbs \\
\hline chóla 'without' & chóla 'to be without, lack' \\
etá( há 'from' & etáha 'to be from' \\
iyókogna 'between' & iyókogna 'to be in the middle' \\
khiyélalikhiyela 'near, close to' & khiyélalikhiyela 'to be close to' \\
ohómnila'óhomni 'around' & ohómnila'óhomni 'to go around' \\
(a')ókšą 'around' & $a$ 'ókša 'to go around' \\
ú 'because of' & $\dot{u}$ 'to exist, to be at' \\
$\dot{u}$ 'with (INSTRUMENTAL)' & $\dot{u}$ 'to use' \\
yuhá 'with (COMITATIVE)' & yuhá 'to have, take along' \\
\end{tabular}


The morphonological and phonological processes that lead to shortening of étu to él can be summarized as follows. Basically, in Lakota, there are morphosyntactic positions in which word-final vowels following a consonant are dropped. One of these positions is that of final vowel of the first verb in a sequence of two verbs. The verbs étu 'to be there, be at/on, exist, be present, be ready' and nážzi 'to stand' may be serialized this way. The truncation rule would yield the sequence *ét nážzi, which, however, never occurs. This is because Lakota also has a phonological rule which regularly changes word-final [t] to [1], so that *ét is transformed into él. It can be shown that the vast majority of Lakota postpositions developed out of string-initial verbs in serial verb constructions such as él náži (Pustet 2000). The truncated forms became fossilized and independent: finally, they were also used outside of the morphosyntactic environment that conditions truncation, that is, outside of the serial verb constructions they originated in. At this stage, the formal development of the verb étu 'to be there, be at/on, exist, be present, be ready' into the postposition él 'LOCATIVE/DIRECTIONAL' was complete. This process was accompanied by semantic expansion: the postposition él denotes both stasis and motion, whereas the semantic content of the original verb étu lacks the meaning component of motion.

\subsection{The discourse distribution of él and ektá: Diachronic data}

\subsubsection{Dakota texts (Deloria 1932)}

The collection of narratives titled Dakota texts (Deloria 1932) documents the discourse distribution of él and ektá in the Lakota spoken in the 1930s. The statistical analysis of this corpus reveals, for one, that with respect to the overall discourse distribution of the two postpositions, there is a reversal of the situation in contemporary Lakota. In the 1930s, ektá was used much less frequently than él. Two hundred and thirty-one occurrences of the postposition él contrast with only a hundred and one occurrences of the postposition ektá. This yields a ratio of $69.6: 30.4$ percent for él vs. ektá (while the same ratio in contemporary Lakota is 41.3 : 58.7 percent; cf. section 2.2). This difference notwithstanding, the prototype effects

Table 6a. Discourse distribution of él and ektá in Deloria (1932): Raw figures

\begin{tabular}{lccccc}
\hline & \multicolumn{2}{c}{$e ́ l$} & \multicolumn{2}{c}{ ektá } \\
\cline { 2 - 3 } & space & time & & space & time \\
\hline stasis & 123 & 27 & 35 & 5 \\
kinesis & 81 & 0 & 61 & 0 \\
\hline
\end{tabular}




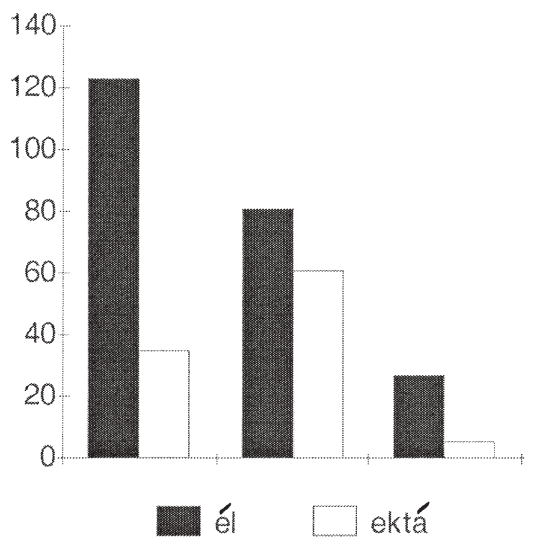

space/stasis space/kinesis time/stasis

Figure 3. Discourse distribution of él and ektá in Deloria (1932)

observed in contemporary Lakota are also present in the Lakota of the 1930s, as the figures reproduced in Table 6a and the corresponding Figure 3 show. For all three semantic feature combinations attested in the corpus, $e ́ l$ is the statistically dominant coding device. Regarding the internal semantic structure of the linguistic categories él and ektá, comparing the data given in Table 6a with the data for contemporary Lakota (cf. Table 3a) does not reveal any major changes. The prototype structures present in contemporary Lakota can also be observed in 1930s Lakota. The relevant percentages are as shown in Table $6 \mathrm{~b}$.

Thus, él exhibits a preference for stasis contexts, while ektá shows a preference for kinesis contexts. Given this, it must be concluded that the dramatic shift in the overall discourse frequencies of él and ektá which took place in the period between Deloria (1932) and Pustet (to appear) did not have any impact on the internal semantic structure of the postpositions él and ektá. This inevitably entails the question of how stable these tendencies were in the development of the language over a longer period of time. In what follows, text data from additional earlier sources will be examined.

Table 6b. Discourse distribution of él and ektá in Deloria (1932): Percentages

\begin{tabular}{lllc}
\hline & space/stasis & space/kinesis & time/stasis \\
\hline él & 53.2 & 35.1 & 11.7 \\
ektá & 34.6 & 60.4 & 5.0 \\
\hline
\end{tabular}


Table 7a. Discourse distribution of él and ektá in Manhart (1978): Raw figures

\begin{tabular}{llcccc}
\hline & \multicolumn{2}{c}{$e ́ l$} & & \multicolumn{2}{c}{ ektá } \\
\cline { 2 - 5 } & space & time & & space & time \\
\hline stasis & 383 & 160 & 22 & 0 \\
kinesis & 160 & 0 & 44 & 0 \\
\hline
\end{tabular}

As it turns out, these data document the logical continuation of the statistical tendencies encountered in comparing contemporary Lakota with the Lakota of the 1930s. On this basis, a coherent chain of events regarding the development of the two postpositions in language history can be reconstructed.

\subsubsection{Lakota Texts and Tales (Manhart 1978)}

The collection of narratives entitled Lakota Texts and Tales (Manhart 1978) was compiled between 1904 and 1921. Most texts were recorded in 1915. In this corpus, there are seven hundred and three occurrences of the postposition él, while ektá is encountered only sixty-six times. This yields a ratio of occurrence for él vs. ektá of $91.4: 8.6$ percent. In other words, in Manhart (1978), él dominates the overall discourse scenario even more clearly than in Deloria (1932).

The relevant statistical figures are reproduced in Table $7 \mathrm{a}$. These figures are given a schematic representation in Figure 4.

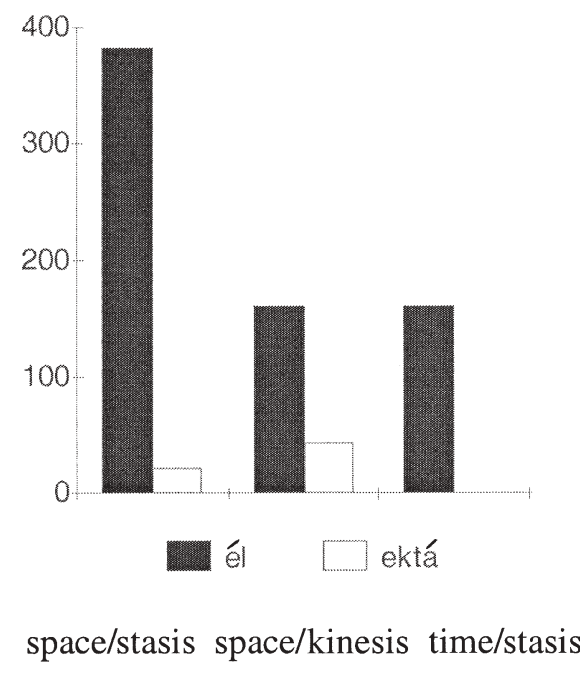

Figure 4. Discourse distribution of él and ektá in Manhart (1978) 
Table 7b. Discourse distribution of él and ektá in Manhart (1978): Percentages

\begin{tabular}{lllc}
\hline & space/stasis & space/kinesis & time/stasis \\
\hline él & 54.4 & 22.8 & 22.8 \\
ektá & 33.3 & 66.7 & 0.0 \\
\hline
\end{tabular}

As for the prototype effects observed in the data from Pustet (to appear) and Deloria (1932), Manhart (1978) yields distributional patterns which are entirely analogous to those found in the later sources. Él clearly "favors" coding stasis - in both of the subdomains space and time - over coding kinesis. Ektá, on the other hand, displays an equally pronounced preference for coding kinesis rather than stasis. The relevant percentages derived from the figures given in Table $7 \mathrm{a}$ are shown in Table $7 \mathrm{~b}$.

3.1.3. Dakota Grammar, Texts, and Ethnography (Riggs 1973 [1893]) The text corpus contained in Riggs (1973 [1893]) is smaller than the other databases analyzed in this study, and it represents the Dakota, rather than the Lakota, dialect of the Sioux language. In this context, it must be pointed out that there is considerable terminological confusion regarding the usage of the label Dakota. Sometimes the Lakota, or Teton, dialect of the Sioux language is referred to as Dakota, although Lakota is clearly distinct from Dakota, phonetically and otherwise (for details, cf. Parks and DeMallie 1992). One of the more regular phonetic differences between Lakota and Dakota affects the pronunciation of one of the postpositions under investigation: the Lakota postposition él is realized as én in Dakota. Just like the Lakota postposition él, the Dakota postposition én derives from the verb étu 'to be there, be at/on, exist, be present, be ready' (for details, cf. section 3). Riggs (1973 [1893]) documents the Dakota dialect of the 1890 s.

The overall ratio of occurrences of én vs. ektá in the Dakota corpus is 42 : 14, i.e., $75: 25$ percent. Thus, as in the two older Lakota sources already dealt with, énlél is the statistically dominant postposition. The distribution of én and ektá within the individual semantic domains is as shown in Table 8a.

Table 8a. Discourse distribution of én and ektá in Riggs (1973): Raw figures

\begin{tabular}{|c|c|c|c|c|}
\hline & \multicolumn{2}{|c|}{ én } & \multicolumn{2}{|c|}{ ektá } \\
\hline & space & time & space & time \\
\hline stasis & 13 & 0 & 5 & 0 \\
\hline kinesis & 29 & 0 & 9 & 0 \\
\hline
\end{tabular}




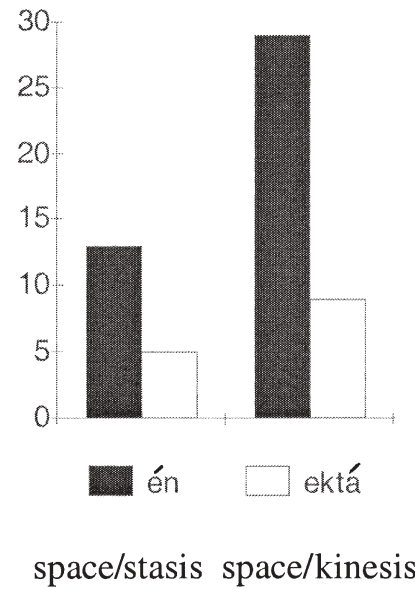

Figure 5. Discourse distribution of én and ektá in Riggs (1973 [1893])

Only two semantic domains are attested in the corpus: space/stasis and space/kinesis. The feature combinations time/stasis and time/kinesis are not documented in the sample. Table $8 \mathrm{a}$ can be converted into Figure 5. Regarding the prototype effects observed in all the Lakota samples investigated for the purpose of this study, the Dakota sample yields an entirely different picture: both én and ektá show a preference for the domain of space/kinesis rather than for the domain of space/stasis. Thus, prototype structures are present here as well, but én and ektá do not display contrastive prototypical cores as in Lakota. The relevant percentages derived from the figures given in Table $8 \mathrm{a}$ are presented in Table $8 \mathrm{~b}$.

The reason for this discrepancy might be dialectal separation, which allowed the Lakota and Dakota dialects of the Sioux language to develop independently (cf. section 3.2).

\subsection{The course of events in diachrony: Summary}

The more or less balanced overall distribution of éllén and ektá found in contemporary Lakota (41.3 : 58.7 percent for él vs. ektá, cf. section 2.1) is not mirrored by the distributional figures obtained for the older text sources for Lakota and the related Dakota dialect which have been analyzed in this study, in which éllén, in any case, is drastically more

Table 8b. Discourse distribution of én and ektá in Riggs (1973): Percentages

\begin{tabular}{lll}
\hline & space/stasis & space/kinesis \\
\hline én & 30.9 & 69.1 \\
ektá & 35.7 & 64.3 \\
\hline
\end{tabular}




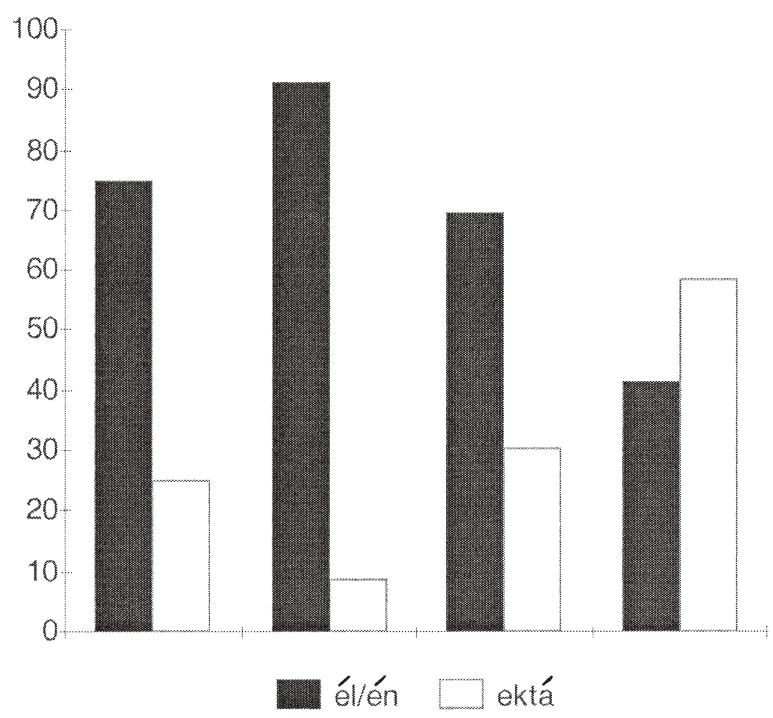

Riggs 1973 Manhart 1978 Deloria 1932 Pustet, to appear

Figure 6. Overall discourse distribution of él/én and ektá in diachronic perspective

frequent than ektá. As a matter of fact, a linear development seems to be taking place in this respect, since the frequency of él in Lakota increases almost proportionately to the age of the data sources, while ektá is relegated to an ever more marginal status, as Figure 6 shows. Put differently, over a time period of about 80 to 90 years, the originally marginal postposition ektá has constantly been gaining ground in Lakota, to the point where its discourse frequency exceeds that of the erstwhile dominant postposition éllén.

The distributional patterns that emerge within a more fine-grained analysis that investigates the distribution of éllén and ektá within each of the semantic domains defined by the features space vs. time and stasis vs. kinesis (cf. Table 1) mirror this steady development. This kind of analysis, however, was conducted in detail only for the domains of space/stasis and space/kinesis. For the third semantic feature combination which occurs in the texts, i.e., time/stasis, no separate analysis is offered here-this semantic domain shows statistical values that correspond closely to those of the feature combination space/stasis in any one of the data sources analyzed, as a glance at the basic Tables $3 \mathrm{a}, 6 \mathrm{a}, 7 \mathrm{a}$, and $8 \mathrm{a}$ reveals. The raw figures for space/stasis and space/kinesis given in the latter tables are summarized in Table 9, and the relevant percentages are added. 


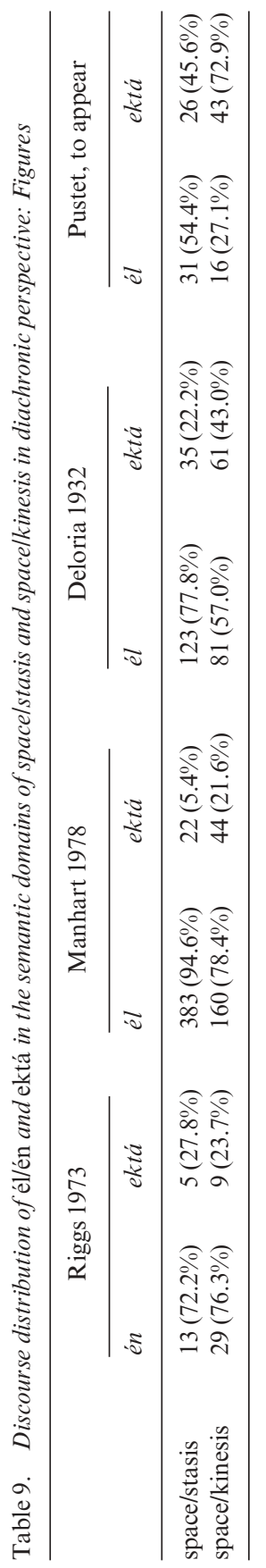




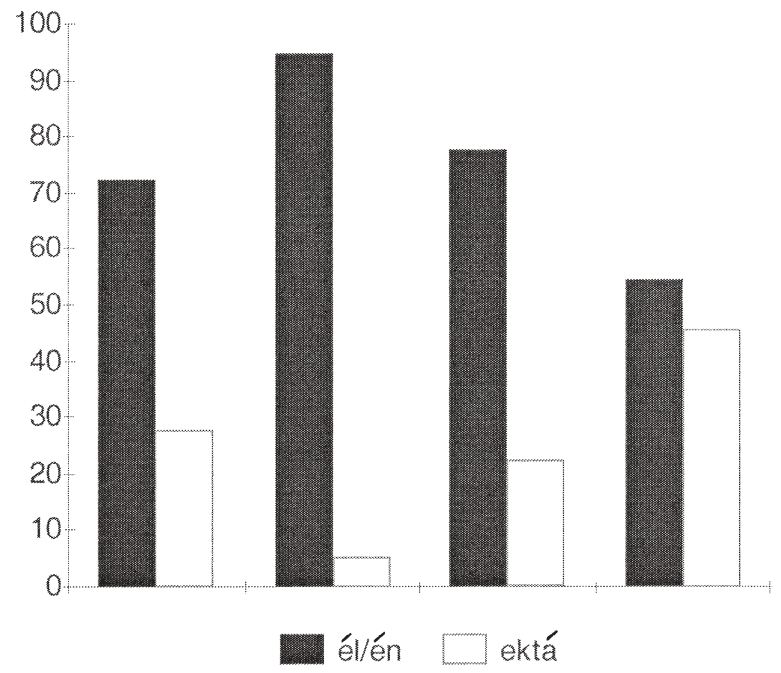

Riggs 1973 Manhart 1978 Deloria 1932 Pustet, to appear

Figure 7. Discourse distribution of él/én and ektá in diachronic perspective: Spacelstasis

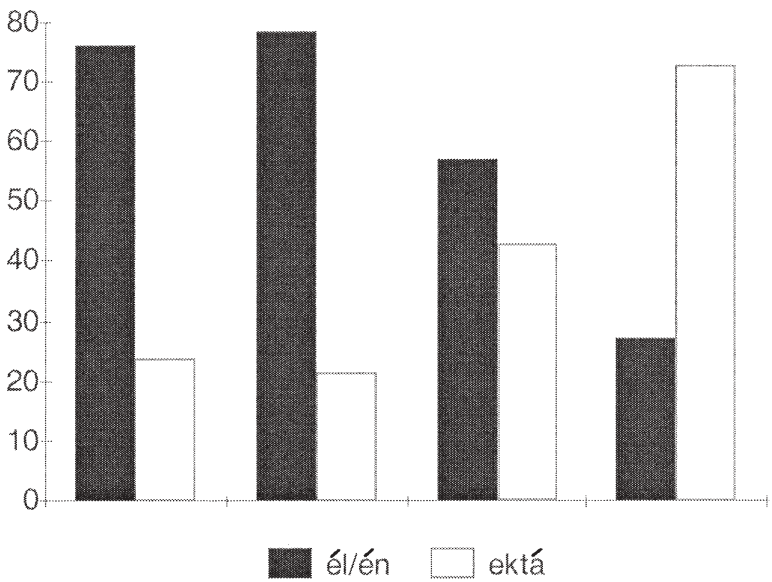

Riggs 1973 Manhart 1978 Deloria 1932 Pustet, to appear

Figure 8. Discourse distribution of él/én and ektá in diachronic perspective: Spacelkinesis 
The percentages presented in Table 9 can be schematized as in Figures 7 (for éllén) and 8 (for ektá). In positions 2, 3, and 4 along the horizontal axis in Figures 7 and 8 the Lakota data are given in chronological order, while position 1 reproduces the data on the Dakota dialect as documented in Riggs (1973 [1893]). The inclusion of the Dakota data in this context is tentative because, as mentioned, Lakota and Dakota are different dialects of the Sioux language. Thus, while the Lakota text samples in Manhart (1978), Deloria (1932), and Pustet (forthcoming) are directly connected genealogically in that they represent successive stages of development within the same linguistic lineage, Dakota constitutes an independent branch in the pedigree of the Sioux language. Due to historical developments, mainly the exodus of the Lakota dialect group to the plains area of the United States, contact between Lakota and Dakota speakers became ever more sporadic after 1750 . As if to prove this point about the increasing geographic isolation of Dakota from Lakota speakers, the behavior of the postpositions én and ektá in Dakota does not really fit into the overall picture gained from the Lakota text materials.

The data on él and ektá in the three Lakota samples, when viewed in chronological order, translate into graphic representations that display linear structures. In the semantic domains of space/stasis and space/kinesis the increase in the relative frequency of use of ektá is as steady and irreversible as the corresponding decrease in the frequency of use of él, as Figures 7 and 8 show. That the evolution of distributional patterns for én and ektá must have taken a slightly different path in Dakota is indicated mainly by the figures for the feature combination of space/stasis. Here the percentage of instances of ektá is far higher than in the Lakota sample which documents approximately the same time stratum, namely, Manhart (1978); the distributional pattern closely resembles that in the more recent Lakota sample from Deloria (1932). Regarding space/kinesis, however, the distributional patterns in the Dakota sample and the temporally corresponding Lakota sample (Manhart 1978) display close parallels.

In sum, for all the older sources investigated, éllén is the statistically dominant coding device in any one of the three semantic domains attested in the texts. But in the Lakota dialect, over the years a steady increase in the percentage of occurrences of ektá as a marker of both the locative and directional roles can be observed, accompanied by a corresponding decrease in the frequency of él. Today, ektá has replaced él as the statistically dominant marker of the directional role; within the domain of locative coding él still holds its dominant position. Given the linearity and continuity in the spread of ektá and the simultaneous decrease in the frequency of él in Lakota, one should expect that él and ektá are 
headed down a diachronic one-way street that sooner or later-provided that the language escapes the imminent threat of extinction-leads to complete loss of él (although it must, of course, be kept in mind that linguistic innovation at any level, be it in phonology, morphology, or syntax, often stops before reaching the point of completion). As an example of the complete replacement of one syntactic element by another, the case of the English anterior can be cited (e.g., Smith 2001). In Old English, there were two competing formats for the expression of the category of anterior. One of these consisted of a past participle plus the auxiliary to have; the other was based on the past participle and the auxiliary to be. The latter construction type was eventually replaced by the former in all contexts in which it occurred. In Modern English, only the have-anterior survives.

The second important point to be made about the discourse behavior of él and ektá in diachronic perspective concerns the internal structure of the categories él and ektá, which display the same contrastive semantic prototypes in all the Lakota text sources investigated, in that each of the two postpositions exhibits a specialization for a different area in semantic space: the semantic prototype for él is the role of locative, and that for ektá the directional. This state of affairs already held in the earliest stratum of the Lakota language accessible for this study, i.e., the Lakota of the early 1900s as documented in Manhart (1978). Despite the subsequent dramatic changes in the overall system, that is, the reversal of the dominance relations between él and ektá with respect to overall discourse frequency, these prototype structures remained remarkably stable. This is indicated in detail by Tables 10 and 11, which represent the figures for éllén and ektá,

Table 10. Discourse distribution of él/én in the semantic domains spacelstasis and spacelkinesis in diachronic perspective: Figures

\begin{tabular}{lllrl}
\hline & $\begin{array}{l}\text { Riggs 1973 [1893] } \\
\text { (Dakota dialect) }\end{array}$ & Manhart 1978 & Deloria 1932 & Pustet, to appear \\
\hline space/stasis & $13(31.0 \%)$ & $383(70.5 \%)$ & $123(60.3 \%)$ & $31(66.0 \%)$ \\
space/kinesis & $29(69.0 \%)$ & $160(29.5 \%)$ & $81(39.7 \%)$ & $16(34.0 \%)$ \\
\hline
\end{tabular}

Table 11. Discourse distribution of ektá in the semantic domains space/stasis and spacelkinesis in diachronic perspective: Figures

\begin{tabular}{lllll}
\hline & $\begin{array}{l}\text { Riggs 1973 [1893] } \\
\text { (Dakota dialect) }\end{array}$ & Manhart 1978 & Deloria 1932 & Pustet, to appear \\
\hline space/stasis & $5(35.7 \%)$ & $22(33.3 \%)$ & $35(36.5 \%)$ & $26(37.7 \%)$ \\
space/kinesis & $9(64.3 \%)$ & $44(66.7 \%)$ & $61(63.5 \%)$ & $43(62.3 \%)$ \\
\hline
\end{tabular}




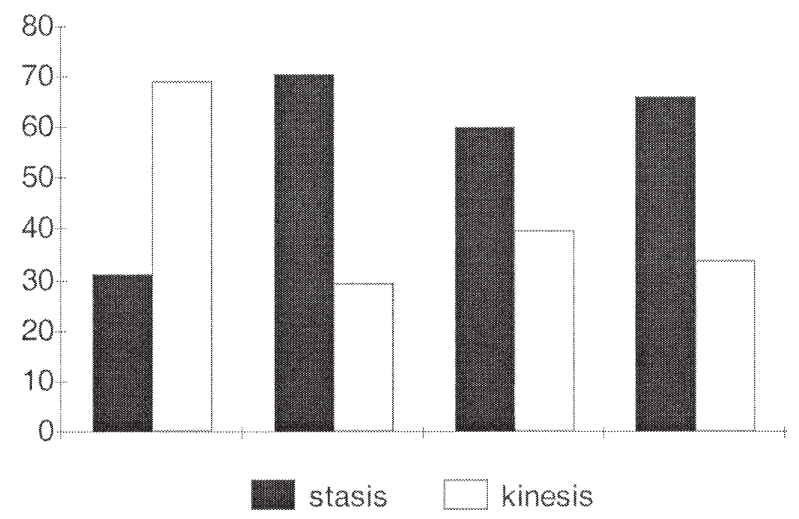

Riggs 1973 Manhart 1978 Deloria 1932 Pustet, to appear

Figure 9. Discourse distribution of él/én in the semantic domains spacelstasis and spacelkinesis in diachronic perspective

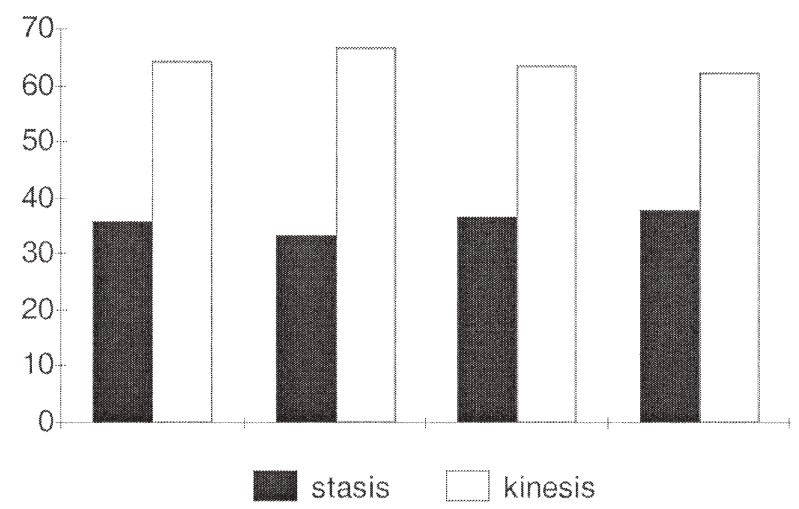

Riggs 1973 Manhart 1978 Deloria 1932 Pustet, to appear

Figure 10. Discourse distribution of ektá in the semantic domains spacelstasis and spacel kinesis in diachronic perspective

respectively, for the domains of space/stasis and space/kinesis (on the basis of the figures given in Tables 3, 6, 7, and 8).

The percentages given in Tables 10 and 11 can be transformed into Figures 9 and 10. Figure 10 shows that with regard to ektá, the Dakota data (cf. first column pair) also conform to the overall picture that emerges 
for Lakota. The behavior of Dakota én, however, diverges from that of its Lakota counterpart él, as Figure 9 reveals. This is, however, not too disturbing because such differences between Dakota and Lakota are to be expected, given that speakers of the two dialects had, by and large, lost regular contact by the mid-1800s (at the latest).

\section{Conclusions}

The basic issue initially addressed in this study concerns the reasons for the general infrequency of full synonymy. In the theoretical literature on the subject, the fact that synonymy violates the principle of economy is identified, via different lines of argumentation, as the basic motivation for the avoidance of synonymy. The hypothesis proposed in this study is that there is an additional area of investigation which offers the opportunity to evaluate potential synonymy relations and which has apparently not been taken into account so far. This area of investigation is frequency distribution in discourse. If two potentially synonymous linguistic items such as the Lakota postpositions él and ektá exhibit contrastive semantic cores by virtue of diverging preferences for the coding of specific meanings in discourse, these linguistic items cannot be claimed to be fully synonymous.

How can such statistical prototype effects be fitted into the general theoretical framework that has been developed to explain what motivates synonymy - or, more accurately, synonymy avoidance? In section 1, it is argued that traditional approaches to the synonymy issue all boil down to the assumption that synonymy violates the principle of iconicity (more specifically, Haiman's principle of isomorphism and Levinson's M-principle, both manifestations of the principle of iconicity), and thus, the principle of cognitive economy. Human language, however, only tolerates and preserves economical structures.

As for the motivation for the existence of prototype structures in human language and cognition, Rosch and her coauthors (1976: 429) hypothesize that the latter might simply arise via imitation of prototype structures encountered in the real world. Biological species, for instance, show prototype effects (Lakoff 1987: 189). The following quotation illustrates in detail what is meant by the claim that extralinguistic reality is organized around prototypes:

In the stimulus sets of the classical concept formation paradigm, attributes are combined arbitrarily to form items. ... However, the contention that the division of real world objects into categories is originally arbitrary would make sense only if the attributes in the world formed a total set...; that is, if all combinations of attribute values were equally likely to occur. For example, consider some of the 
qualities ordinarily treated as attributes in classifying animals: "coat" (fur, feathers), "oral opening" (mouth, beak), and "primary mode of locokinesis" (flying, on foot). If animals were created according to the total set model, then there would be eight different types:

(a) those with fur and mouths, which move about primarily on foot;

(b) those with fur and mouths, which move about primarily by flying;

(c) those with fur and beaks, which move about primarily on foot;

(d) those with fur and beaks, which move about primarily by flying;

(e) those with feathers and mouths, which move about primarily on foot;

(f) those with feathers and mouths, which move about primarily by flying;

(g) those with feathers and beaks, which move about primarily on foot;

(h) those with feathers and beaks, which move about primarily by flying.

... any of the several schemes ... would be equally plausible .... Thus, given the total set type of categorization, it makes sense that the category assignments should be originally arbitrary. However, it hardly requires research to demonstrate that the perceived world of objects is not structured in this manner. Just two of the eight theoretically possible combinations of attribute values, types $a$ and $h$ (mammals and birds, respectively), comprise the great majority of existent species in the world that are possible based on this total set. (Mervis and Rosch 1981: 91-92)

If the "imitation hypothesis" is correct, the existence of prototype structures would derive from the very same basic principle that prohibits the existence of full synonymy, namely, iconicity: categories in human cognition would have to be interpreted as direct copies of, or iconic representations of, extralinguistic reality. However, although the "imitation hypothesis" may be convincing in the context of biological species, its applicability to the particular phenomenon investigated in this study is much less straightforward. What are the ontology-based prototype structures that could be imitated by the Lakota postpositions él and ektá? It appears that there is no answer to this question. Thus, one of the general questions raised by the data on prototype effects in Lakota discourse is whether all types of prototype effects necessarily derive from the same source, i.e., from the imitation of prototype structures found in extralinguistic reality.

At any rate, the most widely accepted hypothesis regarding the motivation for the existence of prototype effects is not the "imitation hypothesis", but rather the assumption that categorization by means of prototypes excels in terms of cognitive economy (e.g., Barsalou and Hale 1993: 115120; Rosch 1978: 37; Rosch et al. 1976: 384). The reasons for the cognitive advantage gained by employing prototype structures in categorization can be summarized as follows: 
The exaggeration of category structure contained in the prototype makes prototypes potentially useful in cognitive processes. Matching to a prototype in categorization would allow humans to make use of their knowledge of the contingency structure of the environment without the laborious process of computing and summing up the validities of individual cues. (Rosch et al. 1976: 434)

Thus, prototype formation in human language and cognition can be interpreted as an attempt to keep linguistic and cognitive organization economical. Since, however, the iconic motivations for synonymy avoidance discussed in section 1 are, ultimately, economy-based as well, both prototype structures and synonymy avoidance serve the purpose of economy maximization. In the specific case of the Lakota postpositions él and ektá, the following hypothesis can, therefore, be proposed. Él and ektá are fully synonymous at the functional level, that is, at the level at which Haiman's principle of isomorphism and Levinson's M-principle apply. These two principles should rule out the existence of this synonymy relation. That this relation nevertheless exists and, moreover, turns out to be extremely stable in the development of the Lakota language, might be due to the fact that the prototype effects observed at the level of the discourse frequency of él and ektá import just about enough economy into the overall constellation to make it "affordable" in cognitive terms. In this context, it should be kept in mind that the prototype structures in the internal semantic profiles of él and ektá which emerge at the discourse level manifest themselves at the cognitive level as well, as the exemplar-naming experiment discussed in section 2.3 suggests.

However, the present investigation, which identifies discourse frequency as one of the descriptive dimensions within which potential synonymy relations can be evaluated, raises some additional questions regarding the synonymy issue. What is the range of discourse-level, synonymy-related prototype effects in a given language as a whole? By and large, the traditional approaches to synonymy dealt with in section 1 are based on data from the lexicon only. Postpositions, however, like adpositions in general, are thought to be somehow intermediate between lexicon and grammar. Are synonymy relations in grammar governed by the same rules as synonymy relations in the lexicon? These considerations outline some of the questions that might have to be addressed by future research into the synonymy issue.

The case of the quasi-synonyms él and ektá, however, could also stimulate further investigations of certain aspects of the dynamics of language change. Grammaticalization theory (e.g., Heine et al. 1991; Hopper and Traugott 1993; Traugott and Heine 1991) states that the grammatical 
inventories of languages are in constant flux because individual grammatical domains are continually being invaded by innovative elements originating either in the lexicon or in other grammatical domains. It is widely known that one of the corollaries of this process is the replacement of old categories with new ones, more accurately, the replacement of old markers of a specific concept or set of concepts with new markers that convey the same meaning (e.g., Heine and Reh 1984: 49, 70-71; Meillet 1958). This process of replacement, however, is slow and gradual; thus the older and the innovative element will exist side by side for quite a while. The inevitable result of this co-occurrence is the emergence of (at least partial) synonymy relations. This aspect of diachronic change has not been studied in great detail so far. Judging from the Lakota data at hand, the postposition ektá is the innovative intruder in the grammatical domain of locative and directional coding, which might, ultimately, replace the competing postposition él, or at least relegate it to a marginal status.

According to Bréal (1897), however, replacement of a given linguistic category by another, that is, complete obsolescence of one form, is only one of the possible ways of terminating a cognitively uneconomical synonymy relation once it arises. The alternative solution to the problem is full functional specialization of the elements involved, i.e., category split: the originally synonymous elements drift apart semantically until, finally, they do not share any meaning components any more and are, consequently, no longer synonymous. This gradual semantic drift in opposed directions might involve the development of the discourse-level prototype effects which are the subject of the present study. Put differently, such prototype structures might, at least in some cases, be created by an attempt to eliminate synonymy relations. This hypothetical scenario, however, is not appropriate for describing the Lakota case. Prototype effects (alias functional specialization) of the postpositions él and ektá are documented in the earliest of the Lakota text sources used for the purpose of this study, and the corresponding distributional patterns remained virtually unchanged throughout the subsequent history of the language, as Figures 9 and 10 indicate. Thus, neither él nor ektá has ever shown any tendency towards increased functional specialization.

Haiman (1985: 23) remarks that, mainly due to the lack of suitable data, little has been done so far to prove that Bréal's model of language change conditioned by synonymy pressure is correct. The present study can, at least, be taken as a piece of empirical support for the validity of one of Bréal's scenarios of synonymy-related language change, i.e., that of the gradual obsolescence of one of the competing forms. Given that within 80 or 90 years, the originally marginal element ektá has rapidly outdistanced 
the originally dominant element él in terms of discourse frequency, and given the continuity and linearity of the spread of ektá and the reduction in the frequency of él, the final result of diachronic change, in this case, might be the complete loss of $e ́ l$ and the complete takeover of the semantic domain in question by ektá.

Received 7 November 2001

Revision received 5 April 2002

University of Colorado

University of Munich

Appendix: Examples of él and ektá in contemporary Lakota discourse, taken from Pustet (to appear)

(1) Text A

ehạni ma-cik'ala k’u héha South Dakota él long ago 1SG.PAT-little when then South Dakota LOC i-má-chare. hé Sichạ́xu oyą́ke él S-1SG.PAT-grow. this Rosebud reservation LOC i-má-chare na he-tá wa-híyu na Oglála S-1SG.PAT-grow and that-from 1SG.AG-come and Oglala $\begin{array}{lllll}\text { makhóce } & \text { ektá } & \text { higgná-wa-thu } & n a & \text { he-tá } \\ \text { country } & \text { LOC } & \text { S-1SG.AG-marry } & \text { and } & \text { that-from }\end{array}$ wašícu makhóce ektá wa-híyu. ho héha eháni white man country DIR 1SG.AG-come. AFF then long ago wa-má-khayeža cha héha iná-wa-ye

ki máni-šni S-1SG.PAT-child QL then mother-1SG.AG-have as the walk-NEG waníyetu wikcémna máni-šni na ąpétu wą él máni-kta year ten walk-NEG and day a LOC walk-FUT yukhá ichưha higná-wa-thu na léchiya then meantime S-1SG.AG-marry and here

$\begin{array}{llll}\text { Oglála } & \text { makhóce } & \text { ektá } & \text { wa-híyu-'. } \\ \text { Oglala } & \text { country } & \text { DIR } & \text { 1SG.AG-come-ASS. }\end{array}$

'A long time ago, when I was little, I grew up in South Dakota, I grew up on the Rosebud reservation, and then I left and married in the Oglala country [Pine Ridge Reservation]. From there I went to the white man's land. Back then, long ago, when I was a child, my mother could not walk. She couldn't walk for ten years, and one day she would walk [after being in the hospital], but meantime I had married and moved there to the Oglala country.' 
(2) Text B

na osní hạ́tahă̌ chąkú na'įšs wakpála ektá aglágla hená and cold when road or river LOC along those héchiya ištiéma-pi na hená héchiya thí-pi. there sleep-PL and those there live-PL.

'And when it is cold they sleep by the roadside or by the creek, and they live there.'

(3) Text C

chưíyaphehe $k i$ hená đ̇̌s eyá cha-yáta yušpí-pi nahá grapes the those 3 also woods-LOC pick-IPS and then hé iyéchel-ya yužáža-pi nahá pus-yá-pi na that like-ADV wash-IPS and then dry-CAU-IPS and

$\begin{array}{lllll}\begin{array}{l}\text { waníyetu } \\ \text { winter }\end{array} & \begin{array}{l}\text { ektá wóżapi berry soup make-IPS } \\ \text { LOC }\end{array} & \begin{array}{l}\text { nahár } \\ \text { and then }\end{array} & \begin{array}{l}\text { hená } \\ \text { those }\end{array} \\ \text { héchus'e } & \text { waníyetu wóyute } & \text { hécha. } & & \\ \text { that way } & \text { winter food } & \text { COP. } & \end{array}$

'Grapes were also picked in the woods, washed the same way, dried, and made into berry soup in winter. They, too were winter food.'

\section{Notes}

* I am indebted to the Lakota native speakers Neva Standing Bear, Florine Red Ear Horse, and $†$ Mary Light for their cooperation, support, and patience in the compilation of the extensive text materials on contemporary Lakota used in this study. Special thanks go to Jan Ullrich for making his electronic versions of some of the other text collections investigated in this project available to me, which greatly facilitated and accelerated the analysis of the data. An earlier version of this article has been presented to audiences at the Research Centre for Linguistic Typology, La Trobe University, Melbourne, and at the International Cognitive Linguistics Conference in Santa Barbara, California, in 2001, and has benefited considerably from the resulting discussions. All remaining errors are my responsibility, of course. Author's email address: <pustetrm@yahoo.com>.

1. The following abbreviations are used in the interlinear glosses in the examples:

$\begin{array}{llll}1 & \text { first person } & \text { FUT } & \text { future } \\ 3 & \text { third person } & \text { IPS } & \text { impersonal } \\ \text { ADV } & \text { adverb } & \text { LOC } & \text { locative } \\ \text { AFF } & \text { affirmative } & \text { NEG } & \text { negative } \\ \text { AG } & \text { agent } & \text { PAT } & \text { patient } \\ \text { ASS } & \text { assertive } & \text { PL } & \text { plural } \\ \text { CAU } & \text { causative } & \text { QL } & \text { qualifier } \\ \text { COP } & \text { copula } & \text { S } & \text { part of verb stem } \\ \text { DIR } & \text { directional } & \text { SG } & \text { singular }\end{array}$




\section{References}

Barsalou, L. W.

1985 Ideals, central tendency, and frequency of instantiations as determinants of graded structure in categories. Journal of Experimental Psychology: Learning, Memory, and Cognition 11, 654-692.

Barsalou, L. W. and C. R. Hale

1993 Components of conceptual representation: From feature lists to recursive frames. In Van Mechelen, I., J. A. Hampton, R. S. Michalski, and P. Theuns (eds.), Categories and Concepts: Theoretical Views and Inductive Data

Bolinger, D.

1977 The Form of Language. London: Longmans.

Bréal, M.

1897 Essai de Sémantique. Paris: Hachette.

Clark, E. V.

1993 The Lexicon in Acquisition. Cambridge: Cambridge University Press.

Deloria, E.

Dakota Texts. New York: Stechert.

Frei, $\mathrm{H}$.

1929 La Grammaire des Fautes. Paris: Geuthner.

Geeraerts, D.

1988 Where does prototypicality come from? In Rudzka-Ostyn, B. (ed.), Topics in Cognitive Linguistics. Amsterdam: Benjamins, 207-229.

Givón, T.

1985 Iconicity, isomorphism and non-arbitrary coding in syntax. In Haiman, J. (ed.), Iconicity in Syntax. Amsterdam: Benjamins, 187-219.

Haiman, J.

1980 The iconicity of grammar: Isomorphism and motivation. Language 56, $515-540$.

1985 Natural Syntax. Iconicity and Erosion. Cambridge: Cambridge University Press.

Heine, B., U. Claudi, and F. Hünnemeyer

1991 Grammaticalization: A Conceptual Framework. Chicago: University of Chicago Press.

Heine, B., and M. Reh

1984 Grammaticalization and Reanalysis in African Languages. Hamburg: Buske.

Hopper, P. J. and E. C. Traugott

1993 Grammaticalization. Cambridge: Cambridge University Press.

Horn, L. R.

1984 Toward a new taxonomy for pragmatic inference: Q-based and R-based implicature. In Schiffrin, D. (ed.), Meaning, Form, and Use in Context: Linguistic Applications. (Georgetown University Round Table 1984.) Washington, DC: Georgetown University Press, 11-42.

Kiparsky, P.

1982 Lexical morphology and phonology. In Linguistic Society of Korea (ed.),

Linguistics in the Morning Calm: Selected Papers from SICOL 1981. Seoul: Hanshin, 3-91.

Lakoff, G.

1987 Women, Fire, and Dangerous Things: What Categories Reveal about the Mind. Chicago: University of Chicago Press. 
Levinson, S. C.

2000 Presumptive Meanings. The Theory of Generalized Conversational Implicature. Cambridge, MA: MIT

Lyons, $\mathrm{J}$.

1968 Introduction to Theoretical Linguistics. Cambridge: Cambridge University Press.

Manhart, P. (ed.)

1978 Lakota Tales and Texts: Wisdom Stories, Customs, Lives, and Instruction of the Dakota Peoples. Written and Compiled by Ivan Stars, Peter Iron Shell, Eugene Buechel; and Dictated by Members of the Oglala and Sicangu Bands of the Southern Lakota Sioux. Pine Ridge, SD: Red Cloud Lakota Language and Cultural Center.

Meillet, A.

1958 Le renouvellement des conjunctions. In A. Meillet Linguistique Historique et [1915/16] Linguistique Générale. Paris: Champion, 159-174.

Mervis, C. B. and E. Rosch

1981 Categorization of natural objects. Annual Review of Psychology 32, 89-115.

Parks, D. R. and R. J. DeMallie

1992 Sioux, Assiniboine, and Stoney dialects: A classification. Anthropological Linguistics 34, 233-255.

Pustet, R.

to appear Lakota Texts. Lincoln: University of Nebraska Press.

2000 Lakota postpositions. International Journal of American Linguistics 66, $157-180$

Rice, J.

1994 Ella Deloria's "The Buffalo People”. Albuquerque: University of New Mexico Press.

Riggs, S. R.

1973 [1893] Dakota Grammar, Texts, and Ethnography. Minneapolis: Ross and Haines.

Rosch, E.

1973 Natural categories. Cognitive Psychology 4, 328-350.

1978 Principles of categorization. In Rosch, E. and B. B. Lloyd (eds.), Cognition and Categorization. Hillsdale, NJ: Erlbaum, 27-48.

Rosch, E., C. B. Mervis, W. D. Gray, D. M. Johnson, and P. Boyes-Braem

1976 Basic objects in natural categories. Cognitive Psychology 8, 382-439.

Smith, K. A.

2001 The role of frequency in the specialization of the English anterior. In Bybee, J. and P. Hopper (eds.), Frequency and the Emergence of Linguistic Structure. Amsterdam: Benjamins, 361-382.

Traugott, E. C. and B. Heine (eds.)

1991 Approaches to Grammaticalization, vol. 1: Focus on Theoretical and Methodological Issues. Amsterdam: Benjamins. 